RESEARCH PAPER RP681

Part of Bureau of Standards Journal of Research, vol. 12, May 1934

\title{
A SENSITIVE INSTRUMENT FOR MEASURING THE AIR PERMEABILITY OF PAPER AND OTHER SHEET MA- TERIALS
}

\author{
By F. T. Carson
}

\section{ABSTRACT}

The new instrument contains a permeability cell of novel design, in which an annular cell surrounds the inner testing cell. By means of this arrangement the usual error from edge leakage is eliminated through the bypassing of the leakage air around the measuring apparatus. The pressures are so adjusted that there is no lateral pressure gradient at the boundary of the test cell and hence no leakage into it. A special pressure regulator has also been designed to maintain a very steady pressure drop across the instrument. The air flow is measured by means of a capillary flow meter, containing four carefully calibrated capillary tubes. The accurate range of the instrument is more than ten thousandfold and approximate measurements can be made over a millionfold range of air permeability values. Since the time element is taken care of in the calibration, tests of relatively impermeable papers are almost as rapid as those of the more porous variety. Results are reproducible on an identical area to within a few tenths of 1 percent. The instrument is well adapted to the testing of leather and some other sheet materials. It will accommodate sheets not thicker than half an inch and it is not necessary to cut the material in order to test it.

\section{CONTENTS}

Page

I. Introduction

II. The problem and the preliminary survey

III. Development of suitable instrument

1. Description of new instrument_... 571

(a) Permeability cell $\ldots$

(b) Means of messuring air flow $\ldots$

(c) Glass-to-metal joints

(d) Manometers and manometer scales........... 573

(e) Testing apparatus for leakage............ 574

(f) Selection of capillary tubes... 574

(g) Pressure regulator

2. Calibration of instrument

3. Performance characteristics

(a) Precision

(b) Accuracy $\ldots$

(c) Rapidity

(d) Range

4. Special precaution in testing thick, laminated materials ... 581

5. Applications and limitations of the new instrument.

IV. References_....... 584

\section{INTRODUCTION}

Notwithstanding the manifold significance of the air permeability of paper and fiber board, the literature on the measurement of this property reveals a field imperfectly explored and replete with differ- 
ences of opinion about the influence of such experimental conditions as the pressure difference across the sheet, the area and thickness of the specimen, the duration of the test, the temperature and relative humidity of the enveloping atmosphere. There are practically no established standards in this field.

Under the program for the investigation, development, and standardization of methods and apparatus for evaluating the properties of paper, an investigation of the air permeability of paper was begun at the instance of the Paper Testing Committee of the Technical Association of the Pulp and Paper Industry, which is interested in establishing a standard method of measuring the air permeability of paper and fiber board.

In addition to furnishing information applicable to the formulation of standards in apparatus, procedure, and units of expression, it was anticipated that the investigation would throw some light on the nature of the fibrous structure in a sheet of paper.

The investigation logically divides itself into two parts: The selection or development of a suitable measuring instrument; and the study of the behavior of paper and fiber boards under different experimental conditions and with reference to the theory of the flow of air through minute passages. The provision of an adequate measuring instrument is dealt with in this paper, whereas the other phase of the investigation will form the subject matter of a second publication.

\section{THE PROBLEM AND THE PRELIMINARY SURVEY}

The requirements in the investigation of variables in the measurement of air permeability, and the bearing of the behavior of these variables upon the structure of paper and upon the problem of standardizing the testing method, demand an instrument having a small experimental error and a range sufficient for the testing of a considerable variety of papers and fiber boards. A survey was first made of designs of apparatus described in the literature to see if any of these instruments could be adapted to the rather exacting requirements of the proposed investigation. The literature reveals a score or more of air-permeability measuring devices adapted to the testing of paper and other fibrous sheet materials. Space permits only the most cursory description of these various designs. References appear at the end of this paper for the convenience of the reader who wishes further details.

According to Herzberg (14), ${ }^{1}$ the earliest form of apparatus was that of Winkler-Karstens, made somewhat on the order of a diminutive gas-meter prover with the paper specimen replacing the upper end of the bell. In this group (group 1) are also the apparatus of Gurley (28), Lhomme et Argy (17), and Barr (1). About three fourths of the designs which have been described make use of some form of measuring flask by which the displacement of a liquid measures the volume of air passing through the specimen, and apparently have been patterned after different forms of gas-measuring and standardizing apparatus. The gas-measuring burette (group 2) is represented by the apparatus of Privett (21), that of Bekk (2), and another of uncertain origin $(12,22)$. The standardizing flask (group 3) is perhaps most frequently represented in the designs offered. In the

\footnotetext{
1 The numbers in parentheses here and throughout the text refer to the references at the end of the Ipape
p. 584 .
} 
apparatus of Sindall (26), Ivanov (15), Bergmann (4), and Silvio (25), the specimen is attached to the flask or disposed in such manner that the inflowing liquid displaces air from the flask through the specimen (subgroup 3a). In the apparatus of Schopper (14) and that of Potts (20), air which is drawn through the paper displaces liquid into a measuring flask (subgroup $3 \mathrm{~b}$ ). The apparatus of Dalen (14) and the Weaver-Pickering apparatus (7) make use of a wet meter to measure the volume of air drawn through the paper (group 4). Emanueli (11), who placed a capillary flow meter in series with the specimen, appears to be the first to make use of the inferential type of gas meter (group 5) in measuring the air permeability of fibrous sheets. The pressure drop through the capillary and that through the paper he measured with water manometers. He then evaluated the rate of flow of air through the paper from these data and a constant of the capillary. This double-flow-meter arrangement has since been used in several instruments: Larson, Nelson, and Bratz (16); Schiefer and Best (23); Doughty, Seborg, and Baird (8); Edwards (9); and Marsh (18). Instruments representative of most of these groups are available from instrument dealers and were studied during the early stages of this investigation.

Most of the apparatus in groups 1,2,3a, and some in group 5 are not designed to permit properly conditioned air to flow through the specimen. The study of the effect of experimental variables requires an adjustable pressure difference across the specimen, which can be held constant during a given test. Instruments of group 1 confine the pressure difference to a single, fixed value. The methods employed in groups $2,3,4$, and 5 to produce a continuous flow of air through the specimen entail either continuous or erratic changes in the pressure difference, unless some means is provided to steady it. A variety of schemes have been used to maintain a constant pressure difference.

The more successful of these employ some form of air vent submerged in water so that a change in line pressure results in a change in the rate of venting rather than in a change in the pressure head. This method, however, is characterized by a continuous pulsation in the pressure difference as the air bubbles form and break away at the end of the submerged vent. Others make use of overflow tanks, large tanks for the displacing liquid, or large reservoirs in the air line, which lessen, but do not eliminate, fluctuations in pressure differences. The auxiliary apparatus is always bulky and not entirely successful. The instruments of groups $1,2,3$, and 4 require the measurement of the time of the relative displacement of a given volume of liquid, which results in a lengthy and tedious test for papers which are not very permeable. Instruments of the first four groups are, for the most part, suited for the measurement of only a rather narrow range of air permeability. In most of the instruments the area tested is very small. It is difficult to estimate the possible precision of the various instruments, but the precision of those available for study seemed inadequate for the present purpose. Without exception, the accuracy of the score or more of instruments is questionable, chiefly because of leakage or uncertainty in the effective area of the specimen. With few exceptions, no method is provided or suggested for testing the apparatus against leakage.

In general the design of the permeability cell is ineffective in that it fails to insure that all of the air which goes through the nominal test 
area, and only this air, passes also through the measuring apparatus. This deficiency becomes serious when one is testing materials having rough or uneven surfaces, materials that are not very permeable, or comparatively thick materials. When these characteristics are all found in a single material the existing designs of testing apparatus are taxed entirely beyond their ability to yield a reliable result. Leakage through the edges of the specimen or between the specimen and the clamping surfaces is sometimes very large. During this preliminary study of available instruments, instances occurred of leakage errors as great as the permeability value itself. It is ironical that, while a number of instruments depend upon clamping the sheet between smooth, annular surfaces to prevent leakage, a recent apparatus (2) is designed to determine the roughness of paper by measuring the rate of this very leakage between the surface of the paper and the clamping surface. In some instruments rubber gaskets and heavy clamping pressure are used to minimize leakage at the edges. These precautions may suffice for thin, smooth papers in which the leakage through the edges of the specimen is negligible, but even in this case the creeping of the rubber under pressure introduces some uncertainty into the effective area tested. The use of gaskets with thicker materials, however, cannot prevent appreciable amounts of air from passing through the edges of the specimen. The most elaborate precautions have been taken by Wilson and Lines (31), Edwards (9), Privett (21), Marsh (18), and Barr (1), who designed their permeability cells so that the edges of the specimen are entirely enclosed and sealed off from the atmosphere. This design lessens, but does not eliminate, movement of air in that portion of the specimen confined between the clamping surfaces. Air must still move outward in the upper levels and inward in the lower levels of this region (if the pressure drop is inward). Although perhaps small for thin sheets, the resulting increase in effective area must be appreciable for thicker materials. Experiments with fiber boards indicate that this tendency is especially pronounced in materials having a laminated structure. The design of Barr, in which the annular enclosed space is evacuated to approximately the pressure within the permeability cell, errs in the opposite direction and leads to permeability values which are too low, because the lateral pressure gradient from the upper periphery of the test area to the annular space must cause a portion of the air which should emerge into the permeability cell to be dissipated into the annular space. One can but repeat the complaint of Potts (20) that all the familiar air permeability testing devices fall short in some respect.

\section{DEVELOPMENT OF SUITABLE INSTRUMENT}

The preliminary survey revealed the inadequacy of available instruments for a thorough investigation of variables in the measurement of the air permeability of paper, and indicated the following major requirements in an improved design: Means of eliminating leakage at the edges of the specimen, and means of testing the apparatus as a whole against leakage; means of maintaining a truly constant pressure difference across the specimen while air, conditioned according to the standard method, is drawn through the specimen; a range of at least several thousandfold to cover the usual types of 
papers and fiber boards; a precise means of measuring the flow of air through the specimen. A very desirable feature to facilitate the investigation is a design permitting fairly rapid testing of materials of low permeability. An additional desideratum is a fairly large specimen interposed in the air stream.

\section{DESCRIPTION OF NEW INSTRUMENT}

Figure 1 illustrates schematically the apparatus devised for the investigation, and figure 2 is a photograph of the instrument.

\section{(a) PERMEABILITY CELL}

The specimen $\mathrm{S}$ is clamped between two elements, each of which is composed of a central cavity or cell $\mathrm{C}$ and an annular cell DD separated by a circular wall terminating in a narrow edge $\mathrm{E}$, less than half a millimeter wide at the line of contact with the specimen. A rubber ring $G$ makes a seal between the annular cell DD and the atmosphere. Conditioned air at atmospheric pressure is accessible to the upper surface of the specimen above both the lower cells $\mathrm{C}$ and DD. By means of an air pump $P$, air is drawn simultaneously from $\mathrm{C}$ and $\mathrm{DD}$, the relative flow being adjusted by valves $\vec{W}$ and $Z$ (for coarse and fine adjustments) until the two menisci of manometer $\mathrm{N}$ are at the same level. Since the horizontal pres-

LIST OF FIGURE NUMBERS AND LEGENDS

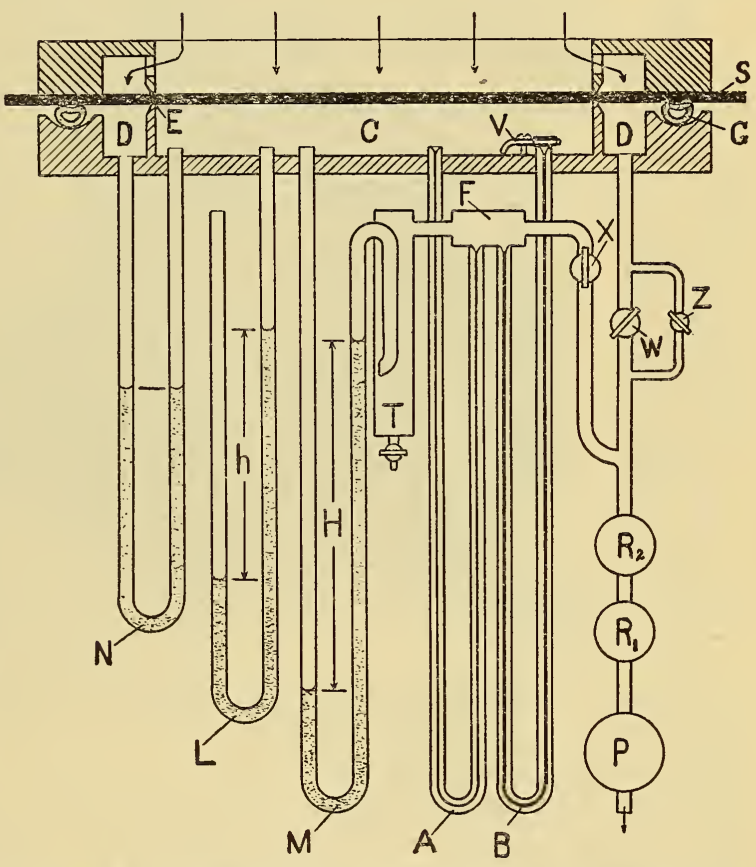

FIGURE 1.-Schematic drawing of the air permeability instrument developed at the Bureau of Standards sure difference across the boundary between the two cells is zero at any level, there can be no edge leakage into or out of cell C. Only the air which comes through that part of the specimen supported above the cell $\mathrm{C}$ is admitted to the measuring device, air reaching DD from the upper surface or through leakage at the edges being by-passed around the meter. The pressure drop through the specimen is measured with the manometer $\mathrm{L}$.

The area of the aperture of the cell $\mathrm{C}$ is $100 \mathrm{~cm}^{2}$. That appreciable sagging or stretching of paper over this large area may be prevented, the specimen is supported by two concentric rings (not illustrated) with very thin contact edges. 
Heavy clamping pressure is not necessary. It is sufficient that good contact is made between the specimen and the bounding edge $\mathrm{E}$. In fact, tests made on a smooth, rather permeable paper without any pressure contact whatever on the specimen above the bounding edge $\mathbf{E}$ (the paper being held only by a narrow clamping ring directly above the rubber ring $\mathrm{G}$ ) indicated that there was practically no movement of air across the clamping surface $\mathrm{E}$ when the menisci of manometer $\mathrm{N}$ were at the same level. Some detail of the clamping mechanism can be seen in figure 2 . The clamping ring $J$ is constrained to move vertically by guides in the ends of two $L$-shaped brackets $K$, and to register accurately with the permeability cell. It lifts high enough to accommodate any sheet material less than half an inch thick. Since it is always convenient, and sometimes necessary, to test a material without having to cut or specially shape it, the clamp is

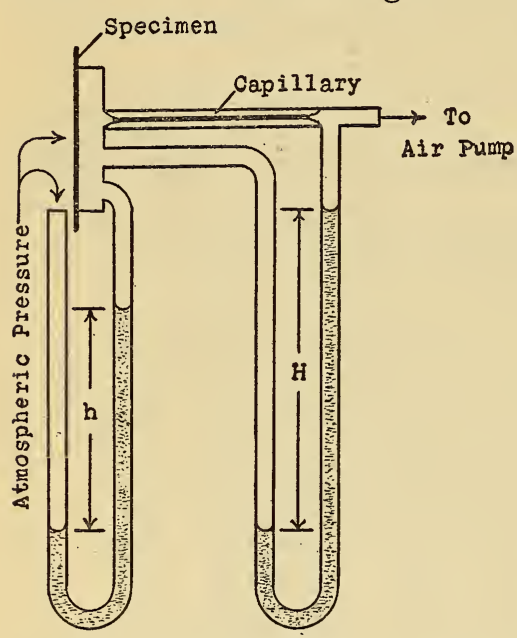

FIgURE 3.-Double-flow-meter method used in measuring the air permeability of paper designed so that it is open on three sides when the ring is lifted. The clamping pressure, which is applied by the handwheel $U$ at the rear, is transmitted through a $\mathrm{Y}$-shaped rocker arm having contact at two opposite points on the clamping ring.

\section{(b) MEANS OF MEASURING AIR FLOW}

The inferential type of flow meter was chosen as preferable to any of the other types for measuring continuous flow of air through materials having such a wide range of air permeability values as paper and fiber boards. It is more versatile and lends itself to more rapid testing and to compactness in design. The double-flow-meter principle of measurement is illustrated in its simplest terms in figure 3, in which a capillary flow meter is placed in series with the specimen arranged as a diaphragm in another flow meter. If the rate of discharge through the capillary tube is known from calibration for all values of the pressure head $H$, the value of $H$ in any given test immediately shows the rate at which air is passing through the specimen under the pressure difference corresponding to $h$. Actual measurements of volume and time are not necessary, since these are made once for all in the calibration. In figure 1 the calibrated flow meter consists of the manometer $\dot{M}$ and 4 capillary tubes of different capacities, of which only $2, \mathrm{~A}$ and $\mathrm{B}$, are shown.

One end of each capillary tube and one limb of each manometer are connected directly into the bottom of the permeability cell. The other end of each capillary tube is connected into a hollow metal block $\mathrm{F}$, leading to the air pump $\mathrm{P}$. A trap T is placed between the manometer $\mathrm{M}$ and this hollow block to prevent the manometer liquid from inadvertently overflowing into the block and entering the capillary tubes. The manometer and trap are connected to the block at the end opposite to the exit to the air pump so that the moving column 
B.S Journal of Research, RP68I

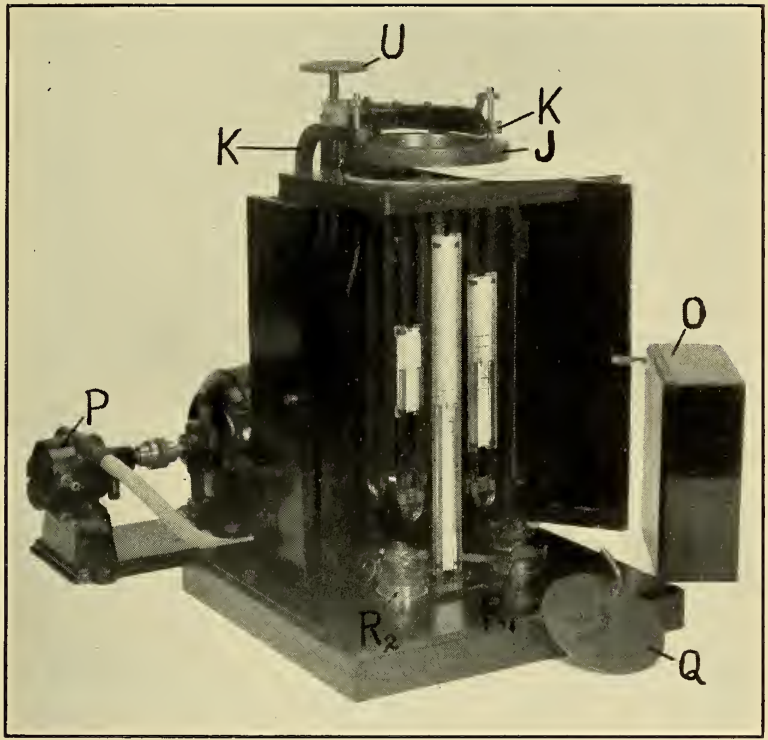

Figure 2.-Photograph of the new instrument. 
B.S. Journal of Research, RP681

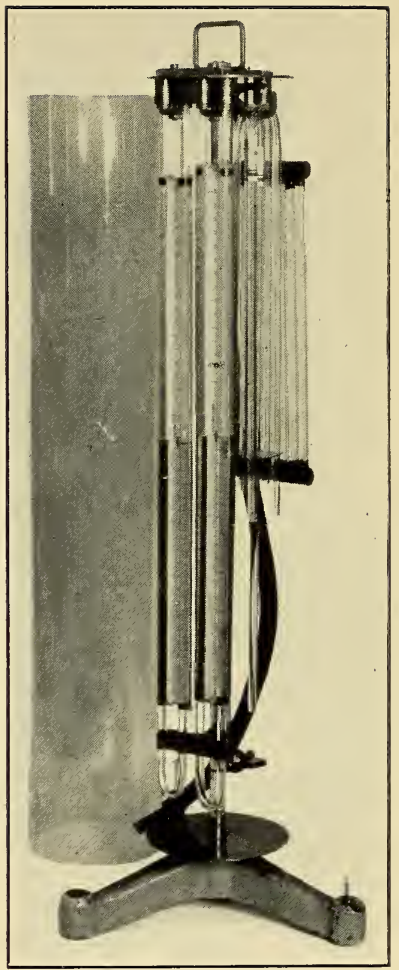

Figure 7.-Calibrated flow meter for the rapid calibration of capillary tubes. 
of air in the hollow block is never a part of the connection between the manometer and the capillary in use.

One end of each capillary opening into the cell $\mathrm{C}$ is provided with a tab valve V, a detail of which is included in figure 4. A flat metal tab, over which is stretched a section of rubber tubing $T$, is pressed down on the end of the tubular projection $\mathrm{P}$ by means of a screw, making an airtight seal. Any one of the capillaries can be connected into the air stream simply by loosening the screw and turning the tab to one side. The tubular projections $\mathrm{P}$ serve also to prevent the manometer liquid from entering the capillary tubes from this end in case of accidental overflow into the permeability cell.

(c) GLASS-TO-METAL JOINTS

Although the connections of the glass capillaries and manometers to the metallic parts of the instrument can be made satisfactorily with good rubber tubing fastened to short metal tubes soldered into the metallic parts, a neater and more satisfactory glass-to-metal joint is illustrated in partial section in figure 4 . The metal $M$ to which the glass tube is to be fastened is drilled so as to leave a conical seat as shown. A short section of rubber tubing $\mathrm{R}$ is cut with a razor

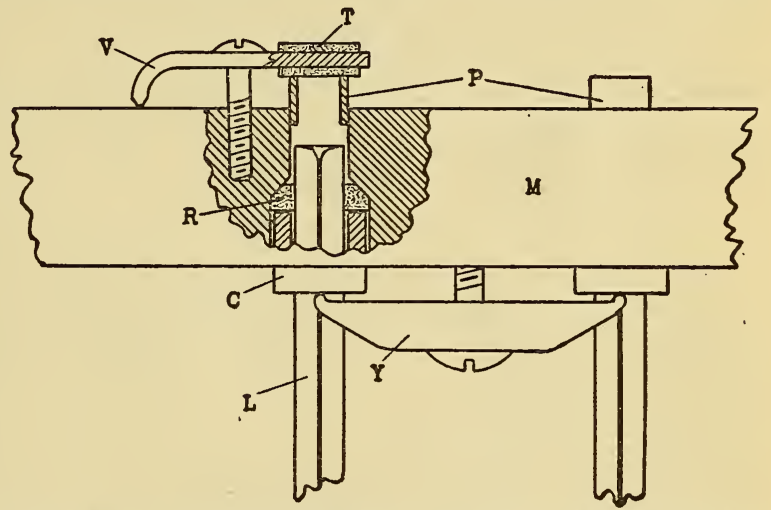

FIGURE 4.-Detail of glass-to-metal joint used in connecting manometers and capillary tubes to the instrument.

blade on a turning head so as to leave smooth ends. This rubber ring should fit snugly about the glass tube $\mathrm{L}$ and loosely in the hole in the metal. A collar $\mathrm{C}$ is forced by a yoke $\mathrm{Y}$ against the rubber ring, which in turn is squeezed into the annular conical space between the glass tube and the metal. A film of moisture applied to the rubber ring makes it seat more readily. The resulting joint is not only airtight, but is flexible and can be easily renewed when necessary. One yoke serves for two adjacent joints.

\section{(d) MANOMETERS AND MANOMETER SCALES}

In figure 2 the manometer on the left with the short scale corresponds to $\mathrm{N}$ of figure 1; the long manometer in the center, to $\mathrm{M}$; and the one on the right, to $\mathrm{L}$. Manometer $\mathrm{N}$ requires no scale other than a horizontal reference mark. The scales of manometers $L$ and $M$ are graduated in millimeters, and are backed by polished sheet metal, the vertical edges of which are bent so as to mirror the menisci of the manometer liquid just to one side of the manometer tubes in order that one may avoid parallax in reading the pressure heads. Since the scale readings are estimated to tenths of a millimeter, the graduations must be quite uniform. The scales are preferably engraved on metal with a dividing engine. Paper scales, however, may 
be used if they are adjusted to the proper length by exposure in air of suitable humidity and then cemented to a metal backing with some such adhesive as cellulose acetate. The scales are fastened to the manometers with spring clips and are adjustable vertically for the zero reading. This adjustment, however, need not be exact, since the readings of the two limbs of each manometer are added to obtain the pressure head. Kerosene was chosen for the manometer liquid because water is likely to give false readings unless the manometer tubes are kept scrupulously clean.

\section{(e) TESTING APPARATUS FOR LEAKAGE}

The specimen $\mathrm{S}$ is replaced by a piece of sheet metal with a soft rubber gasket underneath. A partial vacuum is created in the apparatus and the stopcock $\mathrm{X}$ is closed. If there is a leak anywhere (except in the tab-valves) that would affect the air permeability results, it will be indicated by a drop in the head $h$ of manometer L. As a test for leakage in the tab-valves, which should be made each time a change is made to a different capillary, cell $\mathrm{C}$ is left open at the top, all the capillaries are closed off with their tab-valves, a partial vacuum is created, and stopcock $\mathrm{X}$ is closed. Leakage will be indicated by a drop in head $H$ of manometer $M$.

\section{(f) SELECTION OF CAPILLARY TUBES}

The range of pressure differences selected for the capillary flow meter is 5 to $25 \mathrm{~g} / \mathrm{cm}^{2}$, the upper limit being chosen chiefly for convenience in design, and the lower to insure precise manometer readings. The range of 5 to $10 \mathrm{~g} / \mathrm{cm}^{2}$ was selected for the pressure difference across the specimen, since this pressure difference should be kept as small as practicable to prevent undue stretching of the material tested and to simplify the expression of the results. The ratio of the two pressure differences can, therefore, vary through a tenfold range, and hence each capillary used in the instrument will suffice for a tenfold range of air permeability values if the air flow is approximately proportional to the pressure difference. It was found that most types of paper and fiber board lie within the air permeability range of 0.1 to $5,000 \mathrm{~cm}^{3} / \mathrm{sec} / \mathrm{m}^{2} / \mathrm{g} / \mathrm{cm}^{2}$, and that this range could be fairly well covered with the new instrument by providing it with four capillaries having discharge rates of $0.01,0.1,1$, and 10 liters per minute at a pressure difference of $25 \mathrm{~g} / \mathrm{cm}^{2}$.

It is preferable to have the bore of the capillaries as large as possible to minimize the chance of obstruction by foreign particles. A large test area contributes to the possibility of using larger bores for a given permeability range. The capillaries should be of glass that one may more readily detect obstructing particles, since the danger of fouling is the chief objection which has been offered to the use of capillary flow meters. The length should also be as great as practicable, since it must be very great in comparison with the diameter of the bore if the rate of discharge is to be even approximately proportional to the pressure difference. All but one of the capillaries in the instrument are about 2 feet long.

Capillary tubes of the required length and capacity were selected with the help of data published by Benton (3) so that the discharge 
rates at a pressure difference of $25 \mathrm{~g} / \mathrm{cm}^{2}$ would be well below the critical velocity, since the calibration is very uncertain in the neighborhood of the critical velocity. It is not practicable to select the capillaries from dimensional measurements alone, since very small differences in bore make considerable differences in discharge rate. From a large number of capillaries a considerable number were selected having bores of approximately the desired size. The discharge rates of these were then roughly measured with a previously calibrated capillary flow meter. From these measurements it was possible to select three approximating the requirements enumerated above for the first three capacities. These were bent in a U-shape to conserve space in the instrument. For the largest capacity required a single capillary 2 feet long was not satisfactory, since the critical velocity was exceeded for the higher pressure differences. A satisfactory capillary was made by connecting in parallel a number of smaller capillary tubes, as illustrated in figure 5. Air enters through a short connection into a brass tube into which seven straight capillary tubes about a foot long are sealed with a cement specially recommended for sealing glass to metal. The air, after passing through the several capillary tubes in parallel, enters another section of the brass tubing and thence out through a longer connection. The design is such that the multiple-tube capillary can be connected to the apparatus in the same manner as the U-shaped capillary tubes.

(g) PRESSURE REGULATOR

With manometer readings being taken to a tenth of a millimeter and the line pressure fluctuating over a range of several millimeters or perhaps a few centimeters, very exacting requirements are made of the pressure regulating device. The regulator shown in figure 6, a form of diaphragm valve, was designed especially for the requirements of the new instrument. A rubber diaphragm D closes one side of the chamber $\mathrm{B}$, which is about 2 inches in diameter. A hollow post $P$ is adjustable vertically with reference to the diaphragm by means of the nut $\mathrm{N}$ threaded over the upper end of the post. The

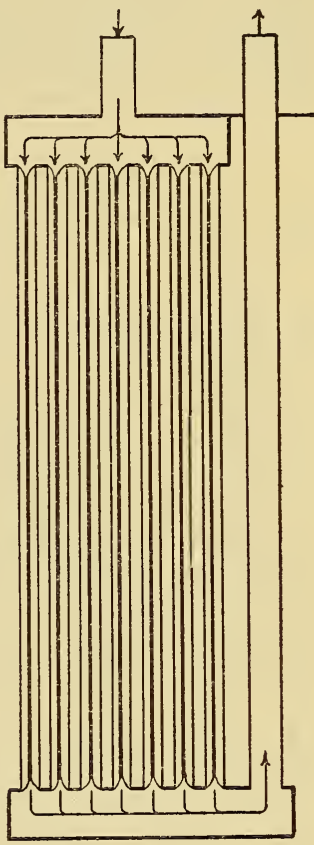

Figure 5.-Multipletube capillary for the larger discharge rates. joints are made tight by means of leather washers $W$, held under mechanical pressure. Air from the chamber B, can pass between the diaphragm and the end of the hollow post, through the orifice into the space $\mathrm{H}$, and out through the hollow cylinder $\mathrm{C}$ to the air pump. The desired pressure difference across the air permeability instrument from $\mathrm{A}$ to $\mathrm{B}$ is obtained by moving the post $\mathrm{P}$ up or down. The pressure difference from $A$ to $B$ is the same as that across the diaphragm and is determined by the position of the diaphragm with reference to the orifice in the lower end of the post $P$. If the pressure in the space $\mathrm{H}$ changes slightly because of an irregularity in the action 
of the air pump, the pressure in B tends to change likewise so as to alter the pressure difference from $A$ to $B$ across the instrument. The slightest change of pressure in $\mathrm{B}$, however, causes the diaphragm to stretch or contract and hence to further close or open the passage from $B$ to $H$. As a result, the rate of escape of air from $B$ is not changed appreciably, and consequently the pressure in $\mathrm{B}$ is not significantly altered. Actually, the weave of pressure in B about the equilibrium position is so small and so rapid that no change can be detected in the manometers except when a very large amount of air is passing through the regulator. When some of the most permeable materials are being tested a very small pulsation can be observed in the manometer levels. Another regulator exactly like the one shown in detail, except for the addition of a needle valve $\mathrm{V}$ through which a certain amount of air can be admitted directly from the atmosphere, is placed in the line just ahead of the air pump. Since the air pump operates at a practically constant capacity, this needle valve is used to by-pass varying amounts of air through the pump, the quantity

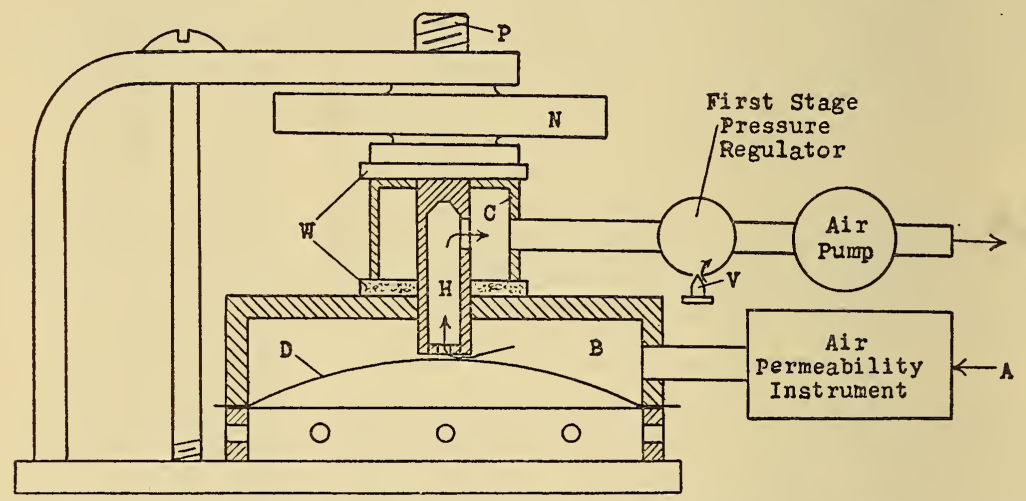

FIGURE 6.-Pressure regulator for controlling the pressure drop across the instrument.

depending upon the amount drawn through the instrument. The first-stage regulator ( $R_{1}$ in figs. 1 and 2$)$ is adjusted for a somewhat greater pressure difference than that desired across the instrument and serves to iron out most of the irregularities before the exact adjustment is made by $R_{2}$.

For the protection of the instrument when it is not in use the front is inclosed by folding panels, and the cell is protected from dust by a removable cover $\mathrm{O}$ (fig. 2 ).

\section{CALIBRATION OF INSTRUMENT}

We have seen from figure 3 that the volume of air flowing per unit time through the specimen under a pressure difference $d=\rho h$, where $h$ is the pressure head across the specimen and $\rho$ is the density of the manometer liquid, is the same as the volume $\phi$ flowing per unit time through the capillary tube under a pressure head $H$. Since we have chosen to measure $\phi$ under the pressure at the inlet side of the capillary we should also measure the volume passing through the specimen under the pressure $B$ on the inlet side of the specimen. If we let $V$ be this volume per unit time, then by Boyle's law $V=\phi \frac{B-d}{B}$. The 
volume $\phi$ corresponding to $H$ is known from the calibration of the capillary, but it is more convenient to have the ratio of $\phi$ to the corresponding pressure difference tabulated against $H$, since this ratio is nearly constant for long capillary tubes and hence the interpolations are very simple. It is also convenient to use the ratio of the two pressure heads. The above equation can, therefore, be written:

$$
V=\frac{H}{h} \cdot \frac{\phi}{\rho H} \cdot \frac{B-d}{B} \cdot d
$$

For values of $B$ within 10 percent of the standard barometric pressure, and $d$ not exceeding $10 \mathrm{~g} / \mathrm{cm}^{2}$, the value of $\frac{B-d}{B}$ will not differ from unity by more than 1 percent ${ }^{2}$ and will not differ by more than 0.1 percent from $1-0.001 \rho h$. Hence equation 1 may be written in the form

$$
\begin{aligned}
\frac{V}{S d} & =\frac{H}{h} \cdot \frac{\phi}{\rho H S}(1-0.001 \rho h) \\
& =\frac{H}{h}(1-0.001 \rho h) C
\end{aligned}
$$

in which $S$ is the effective area of the specimen exposed in the air stream. Although $\rho$ and $S$ are constants of the instrument, the quantity $C=\frac{\phi}{\rho H S}$ is not a constant for a given capillary, but varies somewhat with the pressure difference. The coefficients $C$ have been determined as a function of the pressure head from the calibration of each capillary tube with a primary form of gas meter. The air permeability of a material can, therefore, be determined by substituting in equation 2 the value of the coefficient $C$ for the capillary used corresponding to the pressure head $H, H$ and $h$ being readings in centimeters taken directly from the instrument manometers and $1-0.001$ oh being written down by inspection from the value of $h$ and the constant $\rho$. If $\phi$ is expressed in $\mathrm{cm}^{3} / \mathrm{sec}, \rho H \mathrm{in} \mathrm{g} / \mathrm{cm}^{2}$, and $S$ in $\mathrm{m}^{2}$, equation 2 evaluates the air permeability in cubic centimeters per second per square meter of material for a pressure difference of one gram per square centimeter ${ }^{3}\left(\mathrm{~cm}^{3} / \mathrm{sec} / \mathrm{m}^{2} / \mathrm{g} / \mathrm{cm}^{2}\right)$. It turns out that, since $S$ is about $0.01 \mathrm{~m}^{2}$, the values of $C$ for all four capillaries are greater than unity.

The capillaries were calibrated in place in the instrument, first by a direct method and then by an indirect method. By the direct method, all except the smallest were calibrated by means of a wet meter having a capacity of 0.1 cubic foot per revolution. An accuracy of about 0.2 percent is possible in the measurement of the rate of discharge of a gas with such a meter (29). The calibrating apparatus was arranged in the following order: Atmospheric pressure $\rightarrow$ capillary $\rightarrow$ gas meter $\rightarrow$ pressure regulators $\rightarrow$ air pump. The apparatus was tested for leaks at frequent intervals. All calibrations were made in the standard

${ }^{2}$ Since the variation in air permeability of paper is considerably more than 1 percent, $\frac{H}{h} \cdot C$ in equation 2 represents the value of $\frac{V}{S d}$ sufficiently well for ordinary testing.

${ }^{3}$ The validity of considering $\frac{V}{S d}$ constant for a given specimen is demonstrated within specified limits in the second publication referred to in the introduction. 
atmosphere of 65 percent relative humidity and 21 degrees Centigrade. The gas meter was calibrated at intervals during the calibration of the capillaries by the aspirator-bottle method recommended by Waidner and Mueller (29). The stop watch used was also calibrated and the corrections applied to the data. The meter readings were made in multiples of one complete revolution, and the corresponding time interval varied from 3 minutes to $2 \frac{1}{2}$ hours. The capacity of the least capillary was too small to make feasible its calibration by means of the wet meter. Instead, air was drawn through this capillary by allowing water to flow out of a $200-\mathrm{ml}$ pipette connected to one end of the capillary. As a means of overcoming the pulsation arising from the dropwise flow, the water was led off from the discharge tip for a little distance in an inclined trough. As a means of keeping the pressure head constant, the discharge tip was held at a fixed level while the pipette, connected to it with rubber tubing, was moved vertically with a screw mechanism. The fall in the water level inside the pipette was compensated for by the continuous elevation of the pipette at a suitable rate. The water discharged was caught in a weighing can and weighed on a chemical balance. The resulting weight divided by the density of water at the temperature of the experiment gave the volume of air (measured at the pressure within the pipette) which was drawn through the capillary in a given time and at a given pressure difference across the capillary. In all the calibrations, the measured volume was corrected to the inlet pressure of the capillary. Determinations were made at pressure-head intervals of about 2 centimeters on the manometer scale of the flow meter. For each capillary, the values for the capillary coefficients were plotted against the corresponding pressure heads and a smooth curve was drawn among the points. For the two smaller capillaries this was a straight line. With very few exceptions, the points all lay within 0.2 percent of the curve for each of the four sets of data.

The calibration of a set of capillaries by the foregoing method is very tedious and time consuming. As a convenient means of corroborating the calibration occasionally, and of calibrating replacement capillaries, the standardizing flow meter shown in figure 7 was made. It is provided with a set of four capillary tubes very similar to those in the air permeability instrument. These capillaries were calibrated over a somewhat greater range of pressure differences than were the first set. They are kept covered and are never used except for their intended purpose. With this standardizing flow meter connected in place of the gas meter in the calibration train, the capillaries in the air permeability apparatus were again calibrated by this indirect means. The time was, of course, reduced to a small fraction of that required in the calibration by the direct method. The calibrations by the direct and the indirect methods agreed to within about 0.3 percent except for the largest capillary, for which the agreement was within 0.5 percent.

In table 1 are shown coefficients for the four capillaries corresponding to a few values of the pressure difference. The calibration data for the smallest capillary agree very closely with the theoretical flow of a gas through a long capillary tube, but the agreement for the other three capillaries is less and less satisfactory as the capacity of the capillaries increases. If, instead of experimentally standardizing the capillaries, we should adopt the customary procedure $(8,9,11)$ 
of calculating the theoretical constant ${ }^{4}$ of each capillary from its dimensions and using these values in evaluating the air permeability of paper, we should introduce errors ranging from zero to nearly 50 percent, depending upon the capillary used and the pressure difference.

\section{TABLE 1.-Capillary coefficients for the 4 capillaries of the air permeability instrument at various values of the pressure difference}

\begin{tabular}{|r|r|r|r|r|}
\hline & \multicolumn{4}{|c|}{ Coefficients $C$ for capillary- } \\
\cline { 2 - 5 } $\begin{array}{c}\text { Pressure } \\
\text { difference }\end{array}$ & $C-1$ & \multicolumn{1}{|c|}{$C-2$} & $C-3$ & $C-4$ \\
\cline { 2 - 5 } & & & & \\
\hline $\mathrm{g} / \mathrm{cm}^{2}$ & & & & \\
5 & 1.252 & 10.31 & 94.1 & 749 \\
10 & 1.249 & 10.19 & 88.2 & 690 \\
15 & 1.245 & 10.07 & 83.3 & 644 \\
20 & 1.242 & 9.95 & 79.5 & 606 \\
25 & 1.239 & 9.84 & 76.2 & 571 \\
\hline
\end{tabular}

As confirmation of the continuity of the calibration from one capillary to the next, air permeability tests were made on 16 papers and boards in the 3 transition intervals of the 4 capillaries, an identical area being tested in each case with each of 2 successive capillaries. In nearly all cases the two values thus determined for each material agreed within 0.5 percent. This procedure of making overlapping tests on an identical area of a given material by means of consecutive capillaries is a simple and excellent means of periodically testing the capillaries for accidental fouling that might change the calibration. It dispenses with the necessity for recalibration except when positive evidence of the need is indicated.

For convenience in calculating the results of air permeability tests, complete tables have been prepared from the calibration data which give, for each capillary, the coefficients corresponding to the pressure heads. These tables are, of course, applicable only for a particular density of the manometer liquid and a particular test area of the permeability cell.

TABLE 2.-Air permeability data illustrating the precision and range of the instrument

Filter paper.--

Insulating board

Blotting paper

Antique book paper

Lined strawboard.

Supercalendered book pape

Tagboard.

Bond paper.--

Solid binders board

Pressboard.

Vegetable parchment

\begin{tabular}{|c|c|c|c|}
\hline \multirow{2}{*}{ Thickness } & \multicolumn{3}{|c|}{$\begin{array}{l}\text { Air permeability } \\
\left.\text { (in } \mathrm{cm}^{3} / \mathrm{sec} / \mathrm{m}^{2} / \mathrm{g} / \mathrm{cm}\right)^{2}\end{array}$} \\
\hline & $a$ & $b$ & Difference \\
\hline $\begin{array}{r}m m \\
0.25 \\
11.20 \\
.50 \\
.10 \\
.15 \\
1.10 \\
.05 \\
.25 \\
.10 \\
.45 \\
2.20 \\
.35 \\
.10\end{array}$ & \begin{tabular}{|c}
10,330 \\
2,564 \\
2,226 \\
351 \\
151.1 \\
118.7 \\
86.9 \\
29.80 \\
10.42 \\
2.097 \\
1.595 \\
.1501 \\
.013
\end{tabular} & \begin{tabular}{|c}
10,290 \\
2,558 \\
2,220 \\
349 \\
151.0 \\
119.1 \\
86.9 \\
29.82 \\
10.37 \\
2.100 \\
1.596 \\
.1512 \\
.014
\end{tabular} & $\begin{array}{r}\text { Percent. } \\
-0.4 \\
-. .2 \\
-.3 \\
-.6 \\
-.1 \\
+.3 \\
. .0 \\
+.1 \\
+.5 \\
+.1 \\
+.1 \\
+.7 \\
+7.7\end{array}$ \\
\hline
\end{tabular}

1 This dimensional constant, divided by the coefficient of viscosity of air, is the limiting value, as the pressure difierence approaches zero, of the coefficients in table 1 for each capillary, and hence can be determined also by the extrapolation of these values to zero pressure difference. 


\section{PERFORMANCE CHARACTERISTICS}

\section{(a) PRECISION}

The data in columns $a$ and $b$ in table 2 represent successive tests made on an identical area of a given specimen, and are typical of a great many tests thus made. In the interim between the two tests on each material, the specimen was removed from the tester and the adjustments of the instrument were upset. Most of the data in table 2 have been chosen from results obtained under very exacting conditions, and illustrate other characteristics in addition to precision. In some cases other tests were made during the interim; in some, a day elapsed between the two tests, the specimens being sealed in an airtight package during the interim to prevent appreciable change in the moisture content; some of the stiffer materials were tested first with the supporting ring referred to in a previous section, and then without it; the edges of some of the specimens were dipped in melted wax in the interim between the two tests, and represent a large class of materials referred to in a succeeding section; some specimens were turned upside down for the second test so as to reverse the direction of flow of air, a particularly good example being the lined strawboard which is the most "two-sided" material listed in the table. The agreement of the two results on each specimen is within a few tenths of 1 percent, except for the last entry, the vegetable parchment, which is far beyond the range for which the instrument was designed.

TABLE 3.-Data illustrating the variation in the air permeability of different sheets from the same sample

\begin{tabular}{|c|c|c|c|c|c|}
\hline \multirow{2}{*}{ Kind of material } & \multicolumn{5}{|c|}{$\begin{array}{c}\text { Air permeability (in } \mathrm{cm}^{s} / \mathrm{sec} / \mathrm{m}^{2} / \mathrm{g} / \mathrm{cm}^{2} \text { ) of sheet } \\
\text { number- }\end{array}$} \\
\hline & 1 & 2 & 3 & 4 & 5 \\
\hline $\begin{array}{l}\text { Bond paper. } \\
\quad \text { Do } \\
\text { Ledger paper } \\
\text { Map paper } \\
\text { Strawboard }\end{array}$ & $\begin{array}{c}10.98 \\
206.1 \\
24.2 \\
6.41 \\
160.6\end{array}$ & $\begin{array}{c}11.30 \\
252.1 \\
32.0 \\
8.31 \\
167.5\end{array}$ & $\begin{array}{c}11.80 \\
314.7 \\
38.9 \\
9.26 \\
173.2\end{array}$ & $\begin{array}{c}12.33 \\
355.6 \\
47.0 \\
12.05 \\
176.2\end{array}$ & $\begin{array}{r}12.59 \\
401.9 \\
56.0 \\
14.07 \\
197.1\end{array}$ \\
\hline
\end{tabular}

In contrast with the precision of the instrument, the variability in the air permeability of paper is considerable. Table 3 shows the air permeability values for five sheets taken from each of several samples of paper and board. The variation may be as little as 5 or 10 percent, but it is not unusual to find more than 100 percent spread between the high and low values in a number of sheets from the same sample. ${ }^{5}$

\section{(b) ACCURACY}

It has already been pointed out that an accuracy of about 0.2 percent is possible in the calibration method used, and that the agreement in the calibration data by the two methods used was in most cases within 0.3 percent. Experiments in which the menisci of the manometer connecting the inner and the annular cells were

5 The inherent variability in structure thus indicated is probably the largest factor in the variable nature of the data commonly found in testing the physical properties of paper, which is more of ten blamed on the inadequacy of the method than on the circumstance that we probably do not test enough of the material to fairly sample it. 
adjusted to slightly different levels indicated that the edge-leakage error is probably not greater than 0.3 percent when the test is properly made. Experiments which will be discussed in detail in a succeeding paper indicated that the uncertainty in the effective area exposed to the air stream is probably not greater than 0.5 percent. The readings of the pressure heads are made with an uncertainty of fewer than 5 parts per 1,000 . The value for the density of the manometer liquid, the values of the factor $\frac{B-d}{B}$ in equation 1 , and the tabulated capillary coefficients are expressed within 0.1 or 0.2 percent of the calculated values. The air permeability values obtained with the instrument may, therefore, be conservatively estimated to be within 1 or 2 percent of the true values.

\section{(c) RAPIDITY}

Although time saving is not a primary consideration in precise work, it is a desideratum. In contrast with methods employing the principle of the measuring flask, the character of the paper does not influence very much the time required to complete a test with the new instrument. In most cases it is not necessary to consume time in cutting or specially shaping the specimen. After the adjustments have been made, it is necessary to wait only long enough for pressure equilibrium to be established before the readings are taken, the required time being from a few seconds to perhaps 2 or 3 minutes.

(d) RANGE

The air permeability values in table 2 cover a millionfold range. With the exception of the most impermeable types and possibly a few extremely permeable ones, which require very low scale readings, practically all papers and fibers boards can be tested for air permeability with a reproductibility within less than 1 percent.

\section{SPECIAL PRECAUTION IN TESTING THICK, LAMINATED MATERIALS}

There are certain kinds of materials which are built up in layers, permitting air to travel laterally between the layers with far greater ease than through the layers. The new design of permeability cell may be suspected of inability to prevent entirely the leakage of air through the edges and between the layers of such materials into the inner cell, unless the annular guard cell were made inconveniently wide. The chance of error is greatest for laminated boards of low permeability, especially if a relatively porous core separates dense surface layers. When such materials are tested, tre edges must be dipped in melted wax or otherwise sealed. The wax seal should extend a little distance into the annular cell. To prove that this seal entirely corrects the leakage error, experiments were made with an extreme case of two sheets of paper superimposed and tested, first with free edges, and then with the edges sealed with melted wax. The two sheets were also tested separately. If $a$ and $b$ are the air permeability values of the two sheets tested separately, the air permeability of the two superimposed should be $\frac{a b}{a+b}$. The results in table 4 show that the error resulting from edge leakage in a laminated material may sometimes be considerable, and that it can $49727-34-5$ 
be eliminated by sealing the edges in the manner described. Any material having a thickness approaching the width of the guard cell is likely to give trouble unless the edges are sealed. A very large variety of papers and boards were tested both with and without the wax edge seal, and it was found that none of the papers and very few of the boards required the seal. A piece of leather an eighth of an inch thick showed no difference in air permeability when the edges were left free and when they were sealed. A piece of insulating board (not laminated) half an inch thick did, however, show a difference of about 4 percent.

TABLE 4.-Data showing the necessity of sealing the edges of certain laminated materials

\begin{tabular}{|c|c|c|c|c|c|c|}
\hline \multirow{3}{*}{ Kind of material } & \multicolumn{6}{|c|}{ Air permeability in $\mathrm{cm}^{s} / \mathrm{sec} / \mathrm{m}^{2} / \mathrm{g} / \mathrm{cm}^{2}$} \\
\hline & \multicolumn{2}{|c|}{ Separate sheets } & \multicolumn{4}{|c|}{ Superimposed sheets } \\
\hline & $a$ & $b$ & $\begin{array}{l}\text { Calcu- } \\
\text { lated } \\
\frac{a b}{a+b}\end{array}$ & $\begin{array}{l}\text { Tested } \\
\text { with } \\
\text { sealed } \\
\text { edges }\end{array}$ & $\begin{array}{l}\text { Tested } \\
\text { with } \\
\text { free } \\
\text { edges }\end{array}$ & $\begin{array}{c}\text { Error } \\
\text { without } \\
\text { seal }\end{array}$ \\
\hline $\begin{array}{l}\text { Bond paper } \\
\text { Ledger paper } \\
\text { Wall board } \\
\text { Binders board }\end{array}$ & $\begin{array}{r}5.77 \\
5.18 \\
\end{array}$ & $\begin{array}{r}6.32 \\
5.31 \\
\end{array}$ & $\begin{array}{r}3.017 \\
2.621 \\
\end{array}$ & $\begin{array}{r}3.022 \\
2.619 \\
0.943 \\
.771\end{array}$ & $\begin{array}{l}\text { 3. } 628 \\
\text { 2. } 767 \\
1.080 \\
0.931\end{array}$ & $\begin{array}{r}\text { Percent } \\
20.0 \\
5.7 \\
14.5 \\
20.8\end{array}$ \\
\hline
\end{tabular}

\section{APPLICATIONS AND LIMITATIONS OF NEW INSTRUMENT}

The immediate goal in the development of the new instrument was the study of experimental variables in the measurement of the air permeability of paper and boards, the bearing of these variables upon the structure of paper as revealed through the application of certain theoretical criteria, and the development of information about these variables which might be used in formulating definitions and a standard testing method. This study has been completed and will be described in a subsequent paper.

In addition to the use of the instrument in routine determinations, such as the testing of materials for conformity to specifications, a number of other uses suggest themselves in connection with paper research. It has several times been suggested that the permeability of paper to various processing liquids that do not materially swell cellulose, such as oils, varnishes, waxes, and waterproofing compounds, could be predicted from an air permeability test. The new instrument affords a precise, nondestructive test that might be useful in correlating variations in the common destructive tests, such as tensile, tearing, folding, with variability in the structure of the sheet. It should also be useful in studying the effect of fabrication variables upon the structure of paper, and might turn out to be a valuable control test. Experience with the instrument during the past 2 years indicates that it might be a useful tool in the study of the aging of paper. It holds considerable possibilities in the further study of the structure of paper.

It happens, according to data published by Bergmann and Ludewig (5), that the air permeability of leather lies in practically the 
same range as that of paper and fiber boards, and doubtless this material could be precisely measured with the new instrument without modification.

As the last entry in table 2 indicates, there are certain sheet materials generally classified in the category of paper which are below the range of precise measurement with the instrument which has been described in this paper. The problem can best be visualized by reference to figure 8 . Three sections of the Bureau of Standards have developed permeability measuring instruments with which air permeability measurements have been made within a range of about $10^{12}$. The range of the instruments developed in the textile section (23) and the paper section overlap slightly, so that it is possible to make reliable measurements throughout the regions $\mathrm{C}$ and $\mathrm{D}$; but between the ranges which have been covered by the instruments developed in the gas chemistry section (10) and the paper section there is a considerable region which is largely unexplored, and for which there is apparently no instrument of suitable design. This region includes a group of semi-papers and pseudopapers that are usually classified with paper, such as asphalt saturated

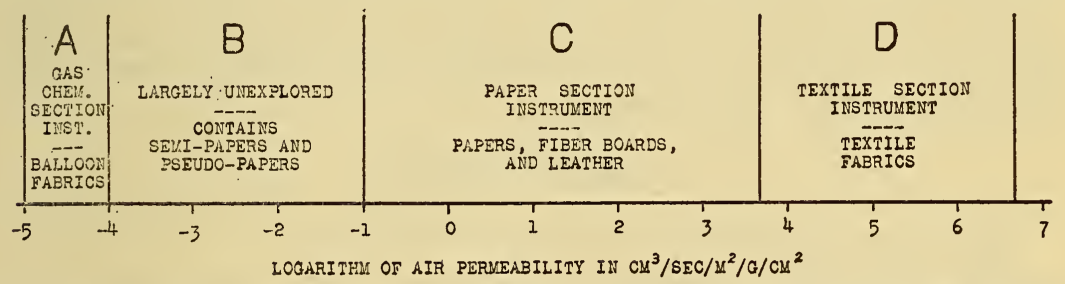

FIGURE 8.-Chart illustrating the range of measurements which have been reported for the air permeability of sheet materials, the range covered by the new instrument, and the region which yet remains to be explored.

papers, asphalt films supported between layers of paper, metal foil between layers of paper, vegetable parchment, glassine, cellophane, and thin films of cellulose nitrate and of cellulose acetate. This region is of considerable interest, not only because of the practical significance of permeability of the materials in this range, but also because the nature of results reported for the behavior of materials at the upper and lower limits of the region indicate a transition in the mechanism of transpiration of gases within this range. A particularly attractive possibility of an instrument sensitive in this region is provided by the suggestion that the "grease resistance" of food wrappers might be predicted from their air permeability. The present tests for grease resistance are rather unsatisfactory, and it would be a great boon if these tests could be replaced by such a simple and dependable test as that for air permeability. Permeability instruments now in use for paper testing are inadequate to test out the suggestion.

The region $\mathrm{B}$ of figure 8 could probably be explored with modified forms of the two instruments which have been used in regions $A$ and $\mathrm{C}$, or by an instrument combining certain features of the two instruments. There appears to be no difficulty in extending the method of measurement with the capillary flow meter down through practically the whole of this region. It is doubtful, however, if it would be sufficient simply to add capillaries of smaller capacity to 
the instrument described in this paper. The relative significance of edge leakage becomes so great, as the permeability comes within this range, that an experimental study would be necessary to determine the suitability for region $\mathrm{B}$ of the method used in region $\mathrm{C}$ to eliminate error from edge leakage. It seems fairly certain, however, that a considerable portion of the region $\mathrm{B}$ could be explored with the new instrument with no significant changes in design except to replace manometer $\mathrm{N}$ of figure 1 with an inclined manometer, provide greater sensitivity in the valves that control the adjustment of this manometer, and add suitable capillary tubes of small capacity.

In both region $\mathrm{B}$ and region $\mathrm{C}$ of figure 8 there are papers, such as fruit wrappers and various food wrappings and cartons, for which the permeability to gases other than air is significant. Permeability studies with various gases could probably be made by the further alteration of the instrument so as to provide a gas-tight seal outside the annular cell, a plate with suitable connections ( $Q$ in figure 2) to close the top of the clamping ring and permit the circulation of a gas through the space above the paper, and a means of readily sweeping out the instrument with the gas before a test is begun.

These brief suggestions, together with figure 8 , will serve to indicate the relation of the new instrument to the problems of permeability as a whole. Applications which have already been made will be discussed in a later paper.

\section{REFERENCES}

1. Barr, The Measurement of the Porosity of Textiles. Jour. Text. Inst., vol. 23, p. 206, 1932.

2. Bekk, Apparatus for Measuring Smoothness of Paper. Paper Trade Jour., vol. 94 (no. 26), p. 41, June 30, 1932.

3. Benton, Gas Flow Meters for Small Rates of Flow. Jour. Ind. Eng. Chem., vol. 11, p. 623, 1919.

4. Bergmann, The Permeability of Hide and Leather. Jour. Int. Soc. Leather Trade Chem., vol. 12, p. 170, 1928.

5. Bergmann and Ludewig, The Permeability of Hide and Leather to Gases. Jour. Int. Soc. Leather Trade Chem., vol. 13, p. 279, 1929.

6. Buckingham, Notes on Small Flow Meters for Air. B.S. Technologic Papers, vol. 14 (T183), 1920.

7. Carson and Worthington, A Study of Sheathing Papers. B.S. Jour. of Research, vol. 3 (RP85), p. 75, 1929.

8. Doughty, Seborg, and Baird, The Volumetric Composition of Paper, IV: Composition of the Air Fraction; Improved Apparatus and Method for Determining Prosity. Tech. Assoc. Papers, vol. 15, p. 287, 1932; Paper Trade Jour., vol. 94 (TS312), 1932.

9. Edwards, The Air Permeability of Leather. Jour. Int. Soc. Leather Trade Chem., vol. 14, p. 392, 1930.

10. Edwards and Pickering, Permeability of Rubber to Gases. B.S. Scientific Papers, vol. 16, p. 327, 1920.

11. Emanueli, The Emanueli Porosity Tester. Paper Trade Jour., vol. 85 (TS98), 1927.

12. Gallagher, Porosity Testing of Paper. Paper, vol. 33 (no. 22), p. 5, Mar. 20,1924 .

13. Hanson, Permeability Versus Porosity of Paper. Paper, vol. 33 (no. 20), p. 11, Mar. 6, 1924.

14. Herzberg, Papierprufung, 6th ed., p. 215, 1927. Verlag von Julius Springer, Berlin.

15. Ivanov, Determining the Porosity of Paper. Paper Trade Jour., vol. 79 (TS147), 1924.

16. Larson, Nelson, and Braatz, Air Infiltration through Various Types of Wall Construction. Heating, Piping, and Air Conditioning, vol. 2, p. 509, 1930.

17. Lhomme et Argy and Bard, The Porosity of Paper to Air. La Papeterie, vol. 53, p. 1438, 1931; Pulp and Paper (Canada), vol. 33, p. 177, 1932. 
18. Marsh, Some Notes on the Permeability of Fabrics to Air. Jour. Text. Inst., vol. 22 (T56), 1931.

19. Meyer, Flow of Gas through Capillary Tubes. Annalen der Physik und Chemie, vol. 127, p. 253, 1866.

20. Potts, The Volumetric Composition of Paper, I: Permeability of Paper to Air. Proc. Tech. Sec. Papermakers' Assoc. Gr. Brit. and Ir., vol. 12, p. 91, 1931; World Paper Trade Rev., vol. 96, p. 1257, 1931.

21. Privett, Permeability Test on Waterproof Boards. World Paper Trade Rev., vol. 96, p. 1436, 1931.

22. Ravizza, The Degree of Porosity of Paper. Paper, vol. 33 (no. 17), p. 14, Feb. 14, 1924.

23. Schiefer and Best, A Portable Instrument for Measuring Air Permeability of Fabrics. B.S. Jour. Research, vol. 6 (RP261), p. 51, 1931.

24. Seborg, Doughty, and Baird, The Volumetric Composition of Paper, V: Composition of the Air Fraction; The Effect of Solid Fraction and Thickness on the Porosity and Air Transmissibility of Simple Papers. Paper Trade Jour., vol. 95 (TS149), 1932.

25. Silvio, The Porosity of Papers. Paper Makers' Mo. Jour., vol. 68, p. 433, 1930 ; and vol. 69 , p. $194,1931$.

26. Sindall, Elementary Manual of Paper Technology, p. 142, 1920. Charles Griffin and Co., London.

27. Stoewer, The Air Permeability of Paper. Wochbl. Papierfabr., vol. 64, p. 57, 1933.

28. U.S. Patent No. $1,538,793$.

29. Waidner and Mueller, Industrial Gas Calorimetry. B.S. Technologic Papers, vol. 4 (T36), pp. 23-40, 1914.

30. Whitehead and Greenfield, Capillary Action in Impregnated Paper Insulation. Physics, vol. 3, p. 324, 1932.

31. Wilson and Lines, The Ventilating Properties of Leather. Ind. Eng. Chem., vol. 17 , p. $570,1925$.

Washington, March 12, 1934. 